\title{
Formation of a Stable Cyano-Bridged Dinuclear Iron Cluster Following Oxidation of the Superoxide Reductases from Treponema pallidum and Desulfovibrio vulgaris with $\mathrm{K}_{3} \mathrm{Fe}(\mathrm{CN})_{6}{ }^{\ddagger}$
}

\author{
Françoise Auchère, ${ }^{\dagger} \S$ Patrícia Raleiras," Linda Benson, ${ }^{\perp}$ Sergei Yu. Venyaminov, ${ }^{\S}$ Pedro Tavares," \\ José J. G. Moura, ${ }^{*, l l}$ Isabel Moura," and Frank Rusnak ${ }^{\dagger, \S}$ \\ Section of Hematology Research, Department of Biochemistry and Molecular Biology, and \\ Biomedical Mass Spectrometry and Functional Proteomics Facility, Mayo Clinic, \\ Rochester, Minnesota 55905, and Centro de Química Fina e Biotecnologia, Departamento de \\ Química, Faculdade de Ciências e Tecnologia, Universidade Nova de Lisboa, \\ 2829-516 Caparica, Portugal
}

Received December 19, 2002

Superoxide reductases catalyze the monovalent reduction of superoxide anion to hydrogen peroxide. Spectroscopic evidence for the formation of a dinuclear cyano-bridged adduct after $\mathrm{K}_{3} \mathrm{Fe}$ $(\mathrm{CN})_{6}$ oxidation of the superoxide reductases neelaredoxin from Treponema pallidum and desulfoferrodoxin from Desulfovibrio vulgaris was reported. Oxidation with $\mathrm{K}_{3} \mathrm{Fe}(\mathrm{CN})_{6}$ reveals a band in the near-IR with $\lambda_{\max }$ at $1020 \mathrm{~nm}$, coupled with an increase of the iron content by almost 2-fold. Fourier transform infrared spectroscopy provided additional evidence with $\mathrm{CN}$-stretching vibrations at 2095, 2025-2030, and $2047 \mathrm{~cm}^{-1}$, assigned to a ferrocyanide adduct of the enzyme. Interestingly, the lowtemperature electronic paramagnetic resonance (EPR) spectra of oxidized TpNIr reveal at least three different species indicating structural heterogeneity in the coordination environment of the active site Fe ion. Given the likely 6-coordinate geometry of the active site $\mathrm{Fe}^{3+}$ ion in the ferrocyanide adduct, we propose that the rhombic EPR species can serve as a model of a hexacoordinate form of the active site.

Superoxide reductases (SORs) play a fundamental role in the defense of anaerobic organisms against oxidative stress by catalyzing the monovalent reduction of the superoxide anion $\mathrm{O}_{2}{ }^{--}$to hydrogen peroxide (eq 1). ${ }^{1-5}$

$\doteqdot$ This paper is dedicated to Prof. Frank Rusnak, who passed away on September 7, 2002, and to his wife Rae and son Leo.

* To whom correspondence should be addressed. E-mail: jose.moura@ dq.fct.unl.pt.

Section of Hematology Research, Mayo Clinic.

$\S$ Department of Biochemistry and Molecular Biology, Mayo Clinic.

${ }^{\perp}$ Biomedical Mass Spectrometry and Functional Proteomics Facility, Mayo Clinic.

"Universidade Nova de Lisboa.

(1) Abreu, I. A.; Saraiva, L. M.; Carita, J.; Huber, H.; Stetter, K. O.; Cabelli, D.; Teixeira, M. Mol. Microbiol. 2000, 38, 322-34.

938 Inorganic Chemistry, Vol. 42, No. 4, 2003

$$
\mathrm{O}_{2}^{\cdot-}+2 \mathrm{H}^{+}+\mathrm{e}^{-} \rightarrow \mathrm{H}_{2} \mathrm{O}_{2}
$$

Enzymes in this family share a conserved active site domain of 100 amino acids accommodating a single Fe ion coordinated by four equatorial histidine nitrogens (three $\epsilon$ and one $\delta$ ) and an axial cysteinyl sulfur atom. ${ }^{6-8}$ Three types of SORs have been characterized, differing primarily in the presence or absence of an $\mathrm{N}$-terminal domain in addition to the active site domain. One group, represented by desulfoferrodoxin (Dfx), binds two $\mathrm{Fe}$ atoms in distinct centers. Besides the active site Fe, Dfx accommodates a second Fe atom within an $\mathrm{N}$-terminal domain coordinated by four cysteines in a distorted tetrahedral geometry similar to desulforedoxin and rubredoxin. ${ }^{9}$ Enzymes in the second group are missing the $\mathrm{N}$-terminal domain and are historically referred to as neelaredoxins (Nlrs), in reference to the prototype from Desulfovibrio gigas. ${ }^{10}$ Neelaredoxin from Treponema pallidum (TpNlr), which has a unique N-terminal domain that does not bind a second $\mathrm{Fe}$ atom, is representative of the third group. ${ }^{2,3}$

(2) Jovanovic, T.; Ascenso, C.; Hazlett, K. R.; Sikkink, R.; Krebs, C.; Litwiller, R.; Benson, L. M.; Moura, I.; Moura, J. J.; Radolf, J. D.; Huynh, B. H.; Naylor, S.; Rusnak, F. J. Biol. Chem. 2000, 275, $28439-48$.

(3) Lombard, M.; Touati, D.; Fontecave, M.; Niviere, V. J. Biol. Chem. 2000, 275, 27021-6.

(4) Lombard, M.; Fontecave, M.; Touati, D.; Niviere, V. J. Biol. Chem. 2000, 275, 115-21.

(5) Jenney, F. E., Jr.; Verhagen, M. F.; Cui, X.; Adams, M. W. Science 1999, 286, 306-9.

(6) Rusnak, F.; Ascenso, C.; Moura, I.; Moura, J. J. Methods Enzymol. 2002, 349, 243-58.

(7) Abreu, I. A.; Xavier, A. V.; LeGall, J.; Cabelli, D. E.; Teixeira, M. J. Biol. Inorg. Chem. 2002, 7, 668-74.

(8) Adams, M. W.; Jenney, F. E., Jr.; Clay, M. D.; Johnson, M. K. J. Biol. Inorg. Chem. 2002, 7, 647-52.

(9) Moura, J. J. G.; Goodfellow, B. J.; Romao, M. J.; Rusnak, F.; Moura, I. Comments Inorg. Chem. 1996, 19, 47-66.

(10) Chen, L.; Sharma, P.; Le Gall, J.; Mariano, A. M.; Teixeira, M.; Xavier, A. V. Eur. J. Biochem. 1994, 226, 613-8.

10.1021/ic0262886 CCC: $\$ 25.00 \quad$ @ 2003 American Chemical Society Published on Web 01/30/2003 

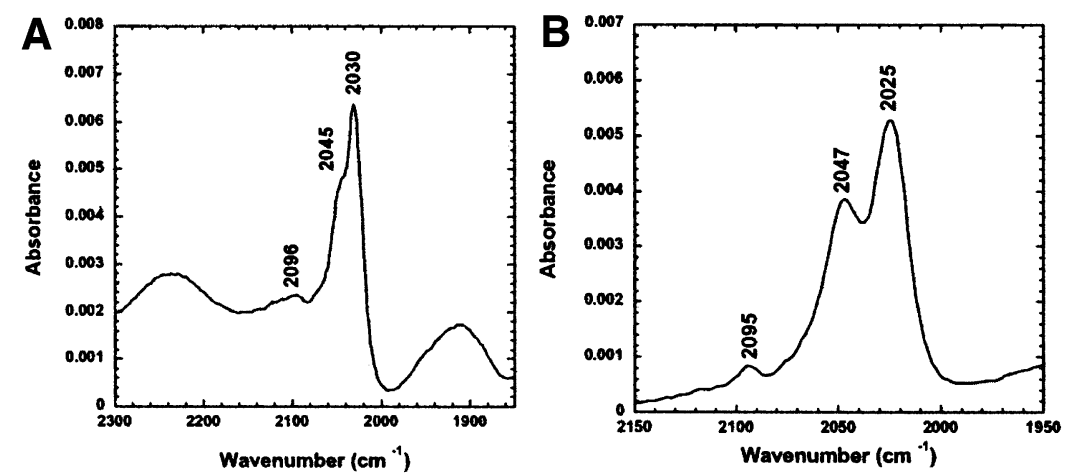

Figure 1. FTIR spectra of SORs after oxidation with $\mathrm{K}_{3} \mathrm{Fe}(\mathrm{CN})_{6}$ : (A) T. pallidum $\mathrm{Nlr}(1.7 \mathrm{mM})$; (B) D. vulgaris Dfx $(0.92 \mathrm{mM})$. Samples in $10 \mathrm{mM}$ Tris- $\mathrm{HCl}$, pH 7.8 were oxidized with a slight excess of $\mathrm{K}_{3} \mathrm{Fe}(\mathrm{CN})_{6}$ at $23{ }^{\circ} \mathrm{C}$, immediately desalted in the same buffer by use of a Sephadex $\mathrm{G}-25$ gel filtration column, and concentrated. Parallel samples of $\mathrm{K}_{3} \mathrm{Fe}(\mathrm{CN})_{6}\left(v=2115 \mathrm{~cm}^{-1}\right)$ and $\mathrm{K}_{4} \mathrm{Fe}(\mathrm{CN})_{6}\left(v=2037 \mathrm{~cm}^{-1}\right)$ were also processed and desalted to verify that the resonances were not due to residual ferri- or ferrocyanide.

Table 1. Metal Ion Stoichiometries of T. pallidum neelaredoxin $(n=$ 3) Oxidized by Four Different Oxidants ${ }^{a}$

\begin{tabular}{lc}
\hline oxidant & iron/protein ratio \\
\hline none & $0.41 \pm 0.12$ \\
$\mathrm{~K}_{3} \mathrm{Fe}(\mathrm{CN})_{6}$ & $0.67 \pm 0.06$ \\
$\mathrm{Na}_{2} \mathrm{IrCl} l_{6}$ & $0.40 \pm 0.04$ \\
$\mathrm{H}_{2} \mathrm{O}_{2}$ & $0.36 \pm 0.05$ \\
$\mathrm{KO}_{2}$ & $0.38 \pm 0.01$
\end{tabular}

${ }^{a}$ Samples were treated and then desalted by rapid gel filtration chromatography. The iron content of each sample was determined by atomic absorption spectroscopy (using $\approx 15 \mu \mathrm{M}$ protein samples), and the protein concentration was measured by use of the Bradford assay with serum albumin as a standard.

The optical spectra of as-isolated TpNlr, or TpNlr oxidized with $\mathrm{H}_{2} \mathrm{O}_{2}, \mathrm{KO}_{2}$, and $\mathrm{Na}_{2} \mathrm{IrCl}_{6}$, exhibit identical sulfur-toiron charge transfer bands at $656 \mathrm{~nm} .^{2,3,10-13}$ Oxidation with $\mathrm{K}_{3} \mathrm{Fe}(\mathrm{CN})_{6}$, however, reveals an additional lower energy band in the near-IR with $\lambda_{\max }$ at $1020 \mathrm{~nm}$ (data in Supporting Information). The latter absorption is characteristic of the charge transfer band observed for the mixed-valence cyanobridged $\left[\mathrm{Fe}^{\mathrm{III}}-\mathrm{NC}-\mathrm{Fe}^{\mathrm{II}}(\mathrm{CN})_{5}\right]$ unit of Prussian blue, ${ }^{14}$ suggesting that ferricyanide oxidation of TpNlr produces a stable ferrocyanide adduct with the active site $\mathrm{Fe}$ iron, in support of a recent proposal. ${ }^{13}$ Consistent with this, the Fe stoichiometry of TpNlr increases following ferricyanide oxidation (Table 1). The Fe stoichiometry of purified TpNlr is 0.41 , indicating the presence of apoprotein in this preparation but in agreement with previous metal analyses of recombinant enzyme produced in Escherichia coli. ${ }^{2,3}$ Following oxidation with $\mathrm{K}_{3} \mathrm{Fe}(\mathrm{CN})_{6}$, but not $\mathrm{H}_{2} \mathrm{O}_{2}, \mathrm{KO}_{2}$, or $\mathrm{Na}_{2} \mathrm{IrCl}_{6}$, the $\mathrm{Fe}$ content increased nearly 2 -fold as would be expected for adduction of a molecule of ferrocyanide to the protein. Similarly, the $\mathrm{Fe}$ stoichiometry of $\mathrm{K}_{3} \mathrm{Fe}(\mathrm{CN})_{6}$-oxidized D.vulgaris Dfx increased $40 \%$ but was unchanged upon oxidation with the other oxidants.

The presence of a ferrocyanide adduct was confirmed by ESI mass spectrometry, which showed the presence of 1 or

(11) Tavares, P.; Ravi, N.; Moura, J. J.; LeGall, J.; Huang, Y. H.; Crouse, B. R.; Johnson, M. K.; Huynh, B. H.; Moura, I. J. Biol. Chem. 1994, $269,10504-10$.

(12) Silva, G.; LeGall, J.; Xavier, A. V.; Teixeira, M.; Rodrigues-Pousada, C. J. Bacteriol. 2001, 183, 4413-20.

(13) Clay, M. D.; Jenney, F. E., Jr.; Hagedoorn, P. L.; George, G. N.; Adams, M. W.; Johnson, M. K. J. Am. Chem. Soc. 2002, 124, 788805.
Scheme 1. Proposed Structure of the Ferrocyanide Adduct

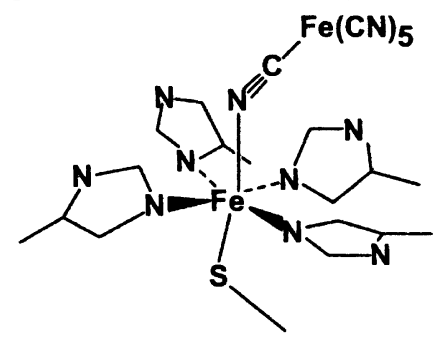

$2 \mathrm{Fe}(\mathrm{CN})_{6}$ adducts of the dimeric protein $\left(\mathrm{MH}^{+}+211.9\right)$ (data in Supporting Information).

Spectroscopic evidence for a ferrocyanide adduct is provided by Fourier transform infrared spectroscopy (FTIR) spectroscopy, which shows characteristic $\mathrm{C}-\mathrm{N}$ stretching bands due to the presence of protein-bound cyanide (Figure 1). In agreement with vibrational studies on similar dinuclear CN-bridged compounds, the $2095 \mathrm{~cm}^{-1}$ stretch can be assigned to the bridging $\mathrm{CN}^{15-24}$ The more intense vibrations, around $2025-2030 \mathrm{~cm}^{-1}$, are assigned to the four equatorial cyanides, while the trans-axial $\mathrm{CN}$ vibrates at higher frequency due to $\sigma$ donation, which strengthens the $\mathrm{C}-\mathrm{N}$ bond. This vibration can be clearly identified in the Dfx spectrum around $2047 \mathrm{~cm}^{-1}$ (Figure 1B). Since $\mathrm{Fe}^{3+}-$ $\mathrm{CN}$ vibrations have been reported to occur at higher frequencies $\geq 2100 \mathrm{~cm}^{-1},{ }^{25}$ these data are consistent with an $\mathrm{Fe}^{2+}$ oxidation state of the $\mathrm{Fe}(\mathrm{CN})_{6}$ group. Moreover, the bridging cyanide vibration around $2095 \mathrm{~cm}^{-1}$ corroborates the orientation of the cyano-bridged structure proposed in Scheme $1 .{ }^{26}$

(14) Robin, M. B. Inorg. Chem. 1962, 1, 337-42.

(15) Doorn, S. K.; Hupp, J. T. J. J. Am. Chem. Soc. 1989, 111, 4704-12.

(16) Walker, G. C.; Barbara, P. F.; Doorn, S. K.; Dong, Y.; Hupp, J. T. J. Phys. Chem. 1991, 95, 5712-5.

(17) Wang, C.; Mohney, B. K.; Williams, R. D.; Petrov, V.; Hupp, J. T.; Walker, G. C. J. Am. Chem. Soc. 1998, 120, 5848-9.

(18) Nakamoto, K. Infrared and Raman spectra of inorganic and coordination compounds; John Wiley and Sons: New York, 1997.

(19) Hester, R. E.; Nour, E. M. J. Chem. Soc., Dalton. Trans. 1981, 939.

(20) Britt, B. M.; Lueck, H. B.; McHale, J. L. Chem. Phys. Lett. 1992, $190,528-32$

(21) Bernhardt, P. V.; Macpherson, B.; Martinez, M. Inorg. Chem. 2000, 39, 5203-8.

(22) Dunbar, K. R.; Heintz, R. A. Prog. Inorg. Chem. 1997, 45, 283-391.

(23) Creutz, C. Prog. Inorg. Chem. 1983, 30, 1.

(24) Haim, A.; Wilmarth, W. K. J. Am. Chem. Soc. 1961, 83, 509.

(25) Noveron, J. C.; Olmstead, M. M.; Mascharak, P. K. J. Am. Chem. Soc. 2001, 123, 3247-59. 


\section{COMMUNICATION}

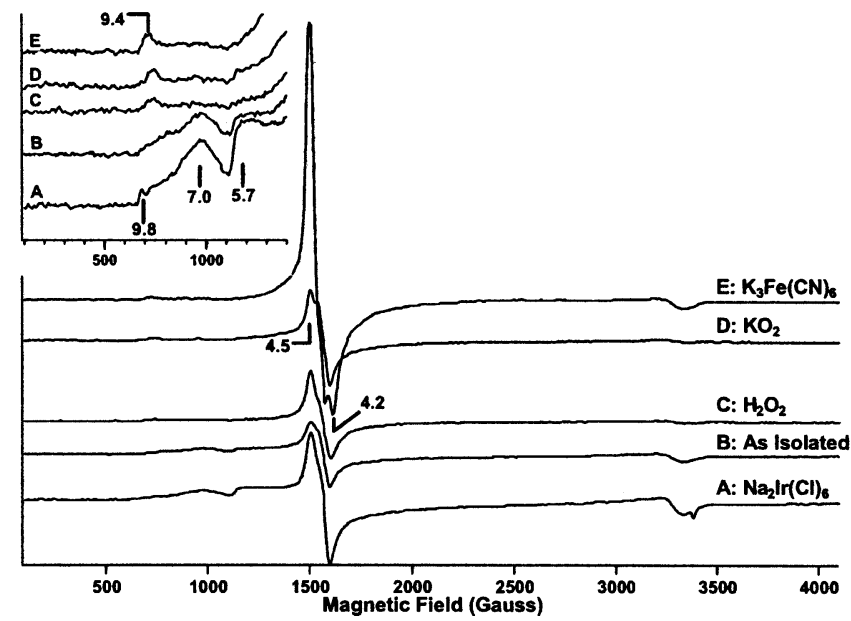

Figure 2. EPR spectra of recombinant Nlr from T. pallidum: (A) Nlr (1.3 $\mathrm{mM})$ oxidized by a slight excess of $\mathrm{Na}_{2} \mathrm{IrCl}_{6}$; (B) as-isolated $\mathrm{Nlr}(0.53 \mathrm{mM})$; (C) $\mathrm{Nlr}(0.45 \mathrm{mM})$ oxidized by 2.7 equiv of $\mathrm{H}_{2} \mathrm{O}_{2}$; (D) Nlr $(0.68 \mathrm{mM})$ oxidized by $\approx 5$ equiv of $\mathrm{KO}_{2}$; (E) Nlr $(0.8 \mathrm{mM})$ oxidized by a slight excess of $\mathrm{K}_{3} \mathrm{Fe}(\mathrm{CN})_{6}$. A slight excess of oxidant is defined as the amount added which no longer produces an increase of the absorbance at $656 \mathrm{~nm}$. After oxidation, all the samples were desalted using a Sephadex G-25 resin to remove excess oxidant. EPR conditions: temperature $3.1 \mathrm{~K}$, microwave frequency $9.48 \mathrm{GHz}$, power $1 \mathrm{~mW}$, modulation $1 \mathrm{mT} / 100 \mathrm{kHz}$.

Interestingly, the low-temperature electronic paramagnetic resonance (EPR) spectra of oxidized TpNlr reveal at least three different species indicating structural heterogeneity in the coordination environment of the active site Fe ion.

As-isolated Nlr exists as a mixture of $\mathrm{Fe}^{2+}$ and $\mathrm{Fe}^{3+}$ forms, with the latter exhibiting an EPR spectrum with $g$ values of 9.8, 7.0, and 5.7 (Figure 2B). The latter two resonances arise from an axial species with $E / D \sim 0.05$ and represent transitions between the $m_{s}= \pm 1 / 2$ and $\pm 3 / 2$ levels of a highspin ferric $S=5 / 2$ spin system, whereas the most low-field resonance arises from a second minor species with $E / D=$ $1 / 3$. As described by Clay et al. for Nlr from Pyrococcus furiosus, the intensity of the axial species increases upon oxidation with $\mathrm{Ir}^{4+} .{ }^{13}$ Although in that study, the more intense, axial feature was attributed to the active enzyme, such a species is not formed following oxidation with the

(26) Shriver, D. F.; Shriver, S. A.; Anderson, S. E. Inorg. Chem. 1965, 4, 725 . physiological substrate, superoxide (Figure 2D), or upon addition of the product $\mathrm{H}_{2} \mathrm{O}_{2}$ (Figure 2C). These oxidants produce yet another rhombic species with a low-field resonance at $g=9.4$ (high-spin $\mathrm{Fe}^{3+}$ component with $E / D$ $=0.25$ ). This rhombic species resembles the EPR spectrum of the magnetically isolated active site $\mathrm{Fe}^{3+}$ ion of the $\left[\mathrm{TpNlr}-\mathrm{Fe}^{\mathrm{III}}-\mathrm{NC}-\mathrm{Fe}^{\mathrm{II}}(\mathrm{CN})_{5}\right]$ unit (Fe ion of the ferrocyanide molecule is low spin, $S=0$ ).

In a recent study on $P$. furiosus, the existence of a ferrocyanide adduct was proposed by Clay and co-workers, ${ }^{13}$ but, to our knowledge, this work constitutes the first bona fide example of a stable, cyano-bridge dinuclear iron cluster with $\mathrm{Fe}(\mathrm{CN})_{6}$ to a metalloenzyme. Moreover, given the likely 6-coordinate geometry of the active site $\mathrm{Fe}^{3+}$ ion in the ferrocyanide adduct, its rhombic EPR spectrum serves as a model of a hexacoordinate form of the active site.

We hypothesize that oxidation with $\mathrm{KO}_{2}$ or $\mathrm{H}_{2} \mathrm{O}_{2}$ yields an analogous octahedral geometry, with a likely sixth ligand being either an aquo or hydroxo species or possibly the carboxylate from glutamate 47 , coordinated to the oxidized iron based on the X-ray structure. ${ }^{27,28}$ Further research is currently in progress to specify the geometry of the active form of the enzyme.

Acknowledgment. The authors thank Drs. Reza Ghiladi and Gang Xing for helpful discussions concerning the spectroscopic characterization of the ferrocyanide adduct. This work was supported by NIH Grant AI-47142 and the European Social Funding within the III Communitary Support Board, and the Fundação para a Ciência e Tecnologia (P.R., Ph.D. Grant SFRH/BD/3095/2000).

Supporting Information Available: Electrospray ionization mass spectra of $\mathrm{K}_{3} \mathrm{Fe}(\mathrm{CN})_{6}$-oxidized Nlr and Dfx. Optical spectra of as-isolated and $\mathrm{K}_{3} \mathrm{Fe}(\mathrm{CN})_{6}$-oxidized Nlr. This material is available free of charge via the Internet at http://pubs.acs.org.

IC0262886

(27) Coelho, A. V.; Matias, P.; Fülöp, V.; Thompson, A.; Gonzalez, A.; Carrondo, M. A. J. Biol. Inorg. Chem. 1997, 2, 680-89.

(28) Yeh, A. P.; Hu, Y.; Jenney, F. E., Jr.; Adams, M. W.; Rees, D. C. Biochemistry 2000, 39, 2499-08. 